\title{
A PERSPECTIVA SÓCIO-CONSTRUTIVISTA NA PSICOLOGIA E NA EDUCAÇÃO: O BRINCAR NA PRÉ-ESCOLA
}

\author{
Vanessa Alessandra Thomaz Boiko* \\ Maria Aparecida Trevisan Zamberlan
}

RESUMO. O artigo aborda o sócio- construtivismo como sistema e seus principais pressupostos, e sua relação com práticas educativas, com a função da escola e do educador. A partir de diretrizes mais gerais, explicita a fundamentação para a proposição de trabalho pedagógico junto à criança na pré-escola, onde o brincar deve ser considerado um componente curricular essencial.

Palavras-chave: sócio-construtivismo, Vygotsky, mediação na construção do conhecimento.

\section{THE SOCIAL CONSTRUCTIVIST APPROACH IN PSYCHOLOGY AND EDUCATION: PLAYING IN PRESCHOOL}

\begin{abstract}
This article discusses the socio-constructivism as a system, its main assumptions and its relation with educational practices, with the school and the role played by the educators. From more general lines, it explains the basis for the proposition of pedagogic work with preschool children, in which "playing" must be considered as an essential curricular component.
\end{abstract}

Key words: socio-constructivism, Vygotsky, knowledge construction.

\section{INTRODUÇÃO}

O sócio-construtivismo é uma teoria que vem se desenvolvendo, com base nos estudos de Vygotsky e seus seguidores, sobre o efeito da interação social, da linguagem e da cultura na origem e na evolução do psiquismo humano. Segundo este referencial, o conhecimento não é uma representação da realidade, mas um mapeamento das ações e operações conceituais que provaram ser viáveis na experiência do indivíduo. Portanto, a aprendizagem é um resultado adaptativo que tem natureza social, histórica e cultural.

O conhecimento culturalmente produzido é um conhecimento "tido-como-partilhado", ou seja, há uma interação negociada pela evolução dinâmica de interpretações, transformações e construções dos indivíduos (Cobb,1998). Na perspectiva de que o processo de desenvolvimento é otimizado pelo aprendizado e que a presença ou a colaboração de outra pessoa mais capaz conduz este processo, o referencial sócio-construtivista situa a educação e a escola como tendo um papel essencial na promoção do desenvolvimento dos indivíduos, e o professor, como planejador, observador, promotor e desafiador do desenvolvimento dos mesmos.

Neste sentido, o papel do professor é caracterizado como o de mediador entre os significados pessoais dos seus alunos e os culturalmente estabelecidos, promovendo $\mathrm{o}$ aprendizado e o desenvolvimento dos mesmos.

Gould (1998) ressalta a colaboração entre coetâneos como igualmente importante para o aprendizado, na medida em que permite ao aluno conduzir e explorar recursos que ele já tinha

Mestre em Educação pelo Programa de Mestrado em Educação da Universidade Estadual de Londrina.

\# Doutora em Psicologia Escolar pela USP - São Paulo. Professora do Departamento de Educação e do Programa de Mestrado em Educação da Universidade Estadual de Londrina.

Endereço para correspondência: Rua Belo Horizonte, 860, ap. 1501, Londrina - Pr. CEP - 86.020-060. Fone: (43) 322.6473.

E-mail: zamba@ldnet.com.br 
disponíveis, mas sobre os quais não havia um controle consciente e explícito.

Nesta perspectiva, Fosnot (1998) reconhece como aspectos essenciais da prática educativa, numa perspectiva sócio-construtivista: permitir que os alunos formulem as próprias perguntas, gerem suas hipóteses e modelos e testem sua validade; proporcionar investigações desafiadoras que gerem possibilidades, tanto corroboradoras quanto contraditórias; incentivar a abstração reflexiva como força dinamizadora da aprendizagem, na medida em que, através dela, os alunos organizam, generalizam e criam sentido para as experiências vivenciadas; incentivar a conversação, a argumentação e a comunicação das idéias e dos pensamentos dos alunos e promover o movimento dos alunos na busca da produção e da construção de significados, movimento este através do qual a aprendizagem impulsiona o desenvolvimento das estruturas psicológicas.

Estas reflexões de Fosnot (1998) sobre a prática pedagógica, endossadas pela perspectiva de outros autores, como Oliveira (1995) e Cerisara (1995), apontam para o desenvolvimento de uma prática intencional, deliberada, dirigida à construção e à apropriação de conhecimentos culturalmente produzidos e à promoção do desenvolvimento, o que significa que não basta a interação social para que o aprendizado ocorra; faz-se necessária uma interação de caráter formativo e proposital.

O referencial sócio-construtivista implica, ainda, uma compreensão da educação e dos fenômenos educacionais como processos em movimento e em transformação, localizando-os dentro de um sistema amplo, que leva em conta a realidade social e histórica em que estão inseridos. Conforme argumenta Cobb (1998), uma análise que tenha como referencial a teoria de Vygotsky não pode isolar um fato da sua situação sócio-cultural.

\section{O DESENVOLVIMENTO HUMANO NUMA CONCEPÇÃO SÓCIO-HISTÓRICA: CONSIDERAÇÕES E IMPLICAÇÕES PARA A EDUCAÇÃO}

\section{A sócio-gênese das funções psicológicas superiores}

Vygotsky (em Vygotsky, Luria \& Leontiev,1988) iniciou seus estudos fazendo uma revisão crítica da história e da situação da Psicologia da sua época. Tendo no Materialismo Dialético a sua mais forte influência, elegeu como objetivo criar uma Psicologia que explicasse o que diferencia o homem dos outros seres da natureza, que explicasse o que faz com que o homem desenvolva, a partir das funções elementares ou biológicas (como por exemplo andar, comer, procriar) o que ele chamou de funções psicológicas superiores (memória, percepção, pensamento, linguagem). Em outras palavras, pretendeu justificar a passagem do homem do estado de natureza ao estado de cultura.

Para explicar esta transformação, este autor considerou os fatores naturais e biológicos, (por exemplo a maturação), como condições necessárias mas secundárias no desenvolvimento das formas complexas de comportamento. Segundo ele, o desenvolvimento é um processo de origem necessariamente social, jamais individual, como entendia a Psicologia de sua época. As funções superiores ou culturais, antes de se constituírem no plano pessoal, já existem no plano social ou interpessoal.

Além de o desenvolvimento psicológico ser considerado pelo autor como um processo eminentemente social, foi entendido também como um processo histórico, não no sentido de uma mera sucessão de fatos no tempo e no espaço, mas de uma seqüência significativa desses fatos, na qual nem o indivíduo e nem o seu ambiente são elementos independentes da sua evolução histórica ou de sua interdependência momentânea. Assim como o sujeito e o objeto são históricos, também a relação entre eles é desta natureza.

Ao falar em relações sociais historicamente produzidas, Vygotsky toma por referência as práticas sociais presentes em determinada época ou cultura, as quais revelam a maneira como os indivíduos se situam uns em relação aos outros: o que pensam e falam; como agem e as implicações da utilização de um sistema simbólico (linguagem) que lhes permite atribuir significados aos objetos, às ações, ao mundo; como utilizam instrumentos através dos quais transformam a natureza conforme o que desejam ou necessitam para sua sobrevivência; e como sofrem a ação recíproca da transformação da natureza por eles modificada.

Concluindo este tópico, na perspectiva vygotskyana as funções psicológicas superiores se desenvolvem nas práticas e pelas práticas sociais, e passam do plano social ao individual através do processo de internalização ${ }^{1}$, que constitui um salto

\footnotetext{
O processo de internalização consiste: (a) na reconstrução e ocorrência interna de uma operação que inicialmente representa uma atividade externa, (b) na transformação de um processo interpessoal num processo intrapessoal e (c) esta transformação de um processo interpessoal num processo intrapessoal é resultado de uma longa série de eventos ocorridos ao longo do desenvolvimento (Vygotsky, 1991, p. 64).
} 
qualitativo através do qual as funções deixam de ser de natureza biológica e passam a ser de natureza cultural.

Desenvolvimento e aprendizado na perspectiva sóciohistórica, e o conceito de "zona de desenvolvimento proximal"

Desde os primeiros dias de vida de uma criança, suas ações e reações adquirem um significado próprio, que lhe é fornecido pelos adultos que asseguram sua sobrevivência física e mediatizam a sua relação com o mundo. Por intermédio destas mediações e das que ocorrem a partir delas, ao longo da vida do indivíduo, o psiquismo humano se desenvolve e a criança internaliza a realidade na qual vive.

Se, numa concepção sócio-histórica, o desenvolvimento das formas complexas de comportamento provém do contato com o ambiente social, a individualidade tem a sua raiz na intersubjetividade. Sobre esta perspectiva Smolka \& Goés (1993, conforme citado por Rego, 1995, p. 62) afirmam:

o que parece fundamental nessa interpretação da formação do sujeito é que o movimento de individualização se dá a partir das experiências propiciadas pela cultura. $\mathrm{O}$ desenvolvimento envolve processos que se constituem mutuamente, de imersão na cultura e emergência da individualidade. Num processo de desenvolvimento que tem caráter mais de revolução que de evolução, o sujeito se faz como ser diferenciado do outro mas formado na relação com o outro: singular, mas constituído socialmente, e, por isso mesmo, numa composição individual mas não homogênea

Endossam esta mesma perspectiva as palavras de Lewontin (1984, p.287, citado por Fosnot, 1998):

O que torna a relação entre sociedade e indivíduo dialética é que os indivíduos adquirem da sociedade produzida por eles propriedades individuais, que eles não possuíam em isolamento. Não se trata apenas de que os todos sejam maiores do que a soma de suas partes; é que as partes se tornam qualitativamente novas por fazer parte do todo.

A importância do papel do outro (social) no desenvolvimento do indivíduo cristaliza-se nas considerações feitas por Vygotsky sobre os processos de desenvolvimento e aprendizado.

Segundo o autor, estes processos se interrelacionam de maneira dinâmica. $\mathrm{O}$ processo de desenvolvimento progride de forma mais lenta que o processo de aprendizado, e este, quando efetuado, converte-se em desenvolvimento.

Oliveira (1995), afirma que o aprendizado possibilita o despertar de processos internos de desenvolvimento que não ocorreriam se não houvesse o contato do indivíduo com certo ambiente cultural.

A relação dinâmica e complexa entre os processos de aprendizado e desenvolvimento é demonstrada no conceito elaborado por Vygotsky (1988) de "zona de desenvolvimento proximal".

Segundo o autor, o "nível de desenvolvimento real" da criança representa a totalidade das funções mentais já completamente desenvolvidas e expressa-se pelas atividades que ela é capaz de realizar sozinha, sem o auxílio de um adulto ou de outra criança mais capaz. Existem ações e soluções de problemas que a criança consegue efetuar na presença de um adulto porém não é capaz de fazê-lo de forma independente e autônoma. Essa condição é referida como "nível de desenvolvimento potencial", ou seja, são habilidades em vias de desenvolvimento. A distância entre o nível de desenvolvimento real e o potencial foi chamada por Vygotsky de "zona de desenvolvimento proximal", designando o patamar no qual as funções ainda não desenvolvidas são impulsionadas pelo aprendizado proporcionado mediante a relação criança-adulto ou criança-pares.

A concepção de que o aprendizado impulsiona o desenvolvimento, assim como a perspectiva sóciohistórica, de forma mais ampla, acarretam algumas implicações para a área da Educação, especialmente no que dizem respeito à ação pedagógica e ao papel do educador.

\section{As implicações do referencial sócio-construtivista para a educação}

Ao encontrar nos métodos e princípios do Materialismo Dialético (principalmente em Hegel) a solução dos paradoxos científicos fundamentais com que se defrontava a Psicologia de sua época, Vygotsky (1987) considerou como ponto central desse método a questão de que todos os fenômenos são estudados como processos históricos em movimento e em mudança.

A educação não pode ser pensada fora desta perspectiva. É fundamental concebê-la como um processo dinâmico e dialético, em que teoria e prática são permeadas pelo contexto social, cultural, econômico e político das diferentes comunidades em que a Educação está inserida.

Se numa concepção sócio-histórica o homem se humaniza, passa da condição de natureza à condição 
humana, na medida em que se apropria das construções culturais do seu grupo, a "Educação" é um dos processos através dos quais esta apropriação é feita. Ela é instrumento de constituição do sujeito, uma vez que oportuniza ao indivíduo internalizar a cultura e se constituir enquanto ser humano.

Sobre a constituição do sujeito, Duarte (1998) afirma que o indivíduo se forma apropriando-se dos resultados da história social e objetivando-se no interior desta história, o que se efetiva sempre no seio de relações concretas com outros indivíduos que atuam como mediadores entre ele e o mundo.

A formação do indivíduo é, portanto, sempre um processo educativo, mesmo quando a relação não é consciente (tanto da parte de quem se educa, quanto da parte de quem age como mediador), e se efetiva sempre no interior de uma determinada prática social.

Sendo assim, a escola, campo da educação formal, não é a única via de acesso ao conhecimento historicamente produzido, mas é a via de acesso formalizada, privilegiada para o educar. Sobre a função da escola, Oliveira (1992, p. 92) afirma: “A escola é o local por excelência para o desenvolvimento do processo de transmissãoassimilação do conhecimento elaborado".

Como local da transmissão-assimilação do conhecimento elaborado a instituição escolar tem o objetivo específico de transformar o saber humano resultado da história das relações de produção dos homens - em saber do aluno. Portanto, a ação pedagógica não é jamais, em momento algum, espontânea ou natural; ela tem objetivos e fins específicos.

Endossando esta visão, Saviani (1995) declara que o trabalho educativo é o ato de produzir, direta e intencionalmente, em cada indivíduo singular, a humanidade que é produzida, histórica e coletivamente, pelo conjunto dos homens.

Sendo assim, na perspectiva destes autores, a educação tem dois objetivos: de um lado, identificar os elementos culturais que precisam ser assimilados pelos indivíduos para que eles se tornem humanos, e, por outro lado, descobrir formas mais adequadas para atingir esse objetivo.

Transformar o saber humano em saber do indivíduo é o grande desafio da educação, eminentemente social, uma vez que: $1^{\circ}$ ) as funções superiores (pensamento, linguagem, percepção, memória) se constituem primeiramente nas e pelas práticas sociais para depois serem internalizadas pelo indivíduo. Elas se constituem no plano das relações para depois se constituírem no plano pessoal, e $2^{\circ}$ ) é a significação da totalidade das produções humanas que constitui a cultura, a qual não pode ser apenas absorvida pelo indivíduo para se constituir enquanto saber, mas precisa ser dotada de significação. É através da mediação do outro, que já apreendeu o significado das coisas e que atribui ao comportamento do indivíduo um significado, que este comportamento se converte de natural em cultural.

Portanto, para que o conhecimento se constitua em saber do indivíduo ele precisa significar o conhecimento, e o significado é atribuído pelo uso da palavra. É através da palavra que o indivíduo nomeia e forma as suas idéias sobre as coisas. É pela palavra que o saber se constitui, circula e é transmitido. Sendo assim, é função da Educação levar os indivíduos a penetrarem no mundo da linguagem e fazerem da prática pedagógica um lugar de circulação da palavra.

Por fim, numa perspectiva sócio-histórica, a Educação deve proporcionar a formação de uma postura crítica por parte do aluno. Para tal, o indivíduo precisa se apropriar tanto do conhecimento quanto do seu processo de produção. Isto significa que o aluno deve ter uma participação ativa no seu processo educativo, superando qualquer forma espontânea e irrefletida de conhecer.

Frente a todas estas questões, não se pode pensar a Educação como isolada de uma reflexão constante: aliando crítica do próprio saber e fazer, da sua constituição histórica nas e pelas práticas sociais e da relação dialética entre ambos.

\section{O papel do educador na constituição de um sujeito sócio-histórico}

O conceito de "zona de desenvolvimento proximal" e a relação entre aprendizado e desenvolvimento nos fazem refletir sobre o papel do educador no desenvolvimento do indivíduo, uma vez que esse processo é impulsionado pelo contato com o ambiente sócio-cultural e pelas aprendizagens ocorridas nestas relações, através da mediação de outras pessoas.

Segundo Vygotsky (Em Vygotsky, Luria \& Leontiev, 1988) o conceito de "zona de desenvolvimento proximal" permite que educadores e professores entendam o curso interno e dinâmico de desenvolvimento, identifiquem quais os processos em maturação já completados e quais estão em formação, para que, com base nestes dados, desenvolvam sua prática. $\mathrm{O}$ autor propõe que o trabalho escolar direcionado aos níveis de desenvolvimento já completados é ineficaz do ponto de vista do desenvolvimento global da criança, uma vez que não é direcionado a um novo estágio de desenvolvimento, A este respeito declara que "o bom aprendizado é 
somente aquele que se adianta ao desenvolvimento" (p.101).

O aprendizado que ultrapassa a "zona de desenvolvimento proximal" foi considerado por Vygotsky tão inadequado quanto o que focaliza as funções já desenvolvidas. Duarte (1998) ressalta que existem limites para a zona de desenvolvimento proximal, isto é, não é tudo que uma criança é capaz de fazer, mesmo com a ajuda de um adulto. Segundo ele, essa é a razão pela qual Vygotsky emprega a palavra "zona", para caracterizar o segundo nível de desenvolvimento. Vygotsky (1988) expressa isto de forma muito clara, quando afirma: "ensinar uma criança aquilo que é incapaz de aprender é tão inútil como ensinar-lhe a fazer o que é capaz de realizar por si mesma" (p. 244-245).

Sendo assim, a escola desempenhará bem seu papel se partir daquilo que a criança já sabe (o conhecimento que ela traz de seu cotidiano, suas idéias a respeito dos objetos, fatos, fenômenos, suas teorias acerca do que observa no mundo) e se for capaz de ampliar e desafiar a construção de novos conhecimentos, estimulando processos internos, que acabarão por se efetivar, passando a constituir a base que possibilitará novas aprendizagens.

O desenvolvimento da ação pedagógica a partir do conhecimento que a criança já tem é fundamental, porque muito antes de uma criança freqüentar uma escola, a partir do contato social dela com seus pais e com o meio em que está inserida, uma série de aprendizados vão se estabelecendo sobre o mundo que a cerca. Ela já entrou em contato com conceitos, valores, idéias e concepções. Já experimentou, observou, imitou, fez perguntas, obteve respostas. Portanto, qualquer situação de aprendizado escolar já tem a sua história prévia.

O conhecimento do nível de desenvolvimento real das crianças é fundamental para que o professor possa intervir nas suas "zonas de desenvolvimento proximal". Esse conhecimento deverá ser considerado como ponto de partida, tanto para novas aprendizagens quanto para o planejamento e a elaboração das atividades a serem desenvolvidas em sala de aula pelos docentes.

Esta perspectiva histórico-cultural coloca o papel do professor numa dimensão diferente daquela na qual ele é visto exclusivamente como agente de informação e transmissão de conhecimentos.

Trata-se da caracterização da diferente extensão que esse nível tem para cada criança, em cada momento de seu desenvolvimento intelectual.
Neste enfoque, ainda que a responsabilidade pela promoção do desenvolvimento e pela constituição de um indivíduo não seja única do professor, ele tem um papel privilegiado neste processo, porque ele é o mediador por excelência da relação que seus alunos estabelecem com o conhecimento produzido pela humanidade.

O mestre é um parceiro privilegiado, porque tem a incumbência, entre outras funções, de tornar acessível ao indivíduo o patrimônio cultural formulado pelos homens ao longo da história.

Cabe a ele maximizar, através da sua relação com os alunos, o desenvolvimento e o aprendizado destes. É nesse sentido que ele tem um papel fundamental na promoção do desenvolvimento individual e na formação dos alunos, enquanto indivíduos autônomos.

Esta reflexão sobre a prática pedagógica e sobre o papel do professor, vista sob o enfoque históricosocial do desenvolvimento humano, aponta para uma concepção de escola em que as pessoas possam dialogar, duvidar, discutir, questionar e compartilhar saberes. Em que haja espaço para transformações, para as diferenças, para o erro, para as contradições, para a colaboração mútua e para a criatividade. Uma escola em que professores e alunos tenham autonomia, possam pensar, refletir sobre o próprio processo de construção de conhecimento e ter acesso a novas informações (Rego, 1995).

\section{O brincar: atividade educativa fundamental na concepção sócio-histórica}

$\mathrm{Na}$ concepção sócio-histórica de educação, o brincar é contemplado como atividade fundamental, uma vez que representa um espaço privilegiado de interação infantil e de constituição do sujeito-criança como sujeito humano, produto e produtor de história e de cultura.

A brincadeira é tida como um dos meios de constituição da subjetividade, porque é através dela que as crianças se apropriam da realidade, bem como a assimilam e recriam.

Vygotsky (1991), no seu livro “A formação social da mente", faz uma análise da brincadeira como atividade não apenas social mas também de natureza e origem específicas, enquanto elementos fundamentais para a construção da personalidade infantil.

Numa situação de brincadeira existe sempre, para aquele que brinca, um certo número de decisões a tomar, de escolhas a fazer, de papéis a assumir. Isto significa que, de forma imaginária, a criança assume diferentes papéis, atribui aos mesmos diversos significados, experimenta situações novas ou mesmo 
do seu cotidiano, testa os valores com os quais se defronta na realidade.

De maneira complementar, as brincadeiras das crianças impõem desafios e questões sobre o seu comportamento diário, e além disso levantam hipóteses, na tentativa de compreender os problemas que lhes são propostos pelas pessoas e pelo ambiente com o qual interagem; assimilam a realidade e, conseqüentemente, a cultura na qual estão inseridas.

Existe, ainda, a possibilidade de recriar a realidade através da utilização de sistemas simbólicos próprios. Segundo Brougère (1997), no brincar pode haver uma mutação do sentido da realidade. Nele, as coisas transformam-se em outras. É um espaço à margem da vida cotidiana, que obedece às regras criadas pela circunstância; espaço em que os objetos podem apresentar-se com significados diferentes daquele que possuem, normalmente.

É, portanto, na situação do brincar que a criança administra a sua relação com o outro e com o mundo, assimila os significados das ações humanas e se apropria deles; testa a sua autonomia e vai se constituindo enquanto sujeito.

Ao definir papéis a serem representados, aferindo significados diferentes aos objetos para uso no brinquedo e no processo de administração do tempo e do espaço (em que se vão definindo os diferentes temas de jogos), as crianças têm a possibilidade de levantar hipóteses, resolver problemas e ir ascendendo, a partir da construção de sistemas de representação, ao mundo mais amplo ao qual, de outra forma, não teriam acesso.

Portanto, a brincadeira é uma situação privilegiada de aprendizado infantil, segundo a qual o desenvolvimento pode alcançar níveis mais complexos, exatamente pela possibilidade de interação entre os pares em uma situação imaginária e pela negociação de regras de convivência e de conteúdos temáticos.

Pelo fato de a brincadeira ser responsável, também, por impulsionar o desenvolvimento, uma vez que nela a criança se comporta além do comportamento habitual da sua idade e além do seu comportamento diário, Vygotsky (1991), considera que a brincadeira cria "zonas de desenvolvimento proximal".

Um outro aspecto importante, dentro da perspectiva histórico-social, é que a brincadeira seja permeada pelo uso de brinquedos. Eles é que representarão os substitutivos dos objetos originais, possibilitando à criança manipulá-los e testá-los, garantindo a apropriação dos mesmos e daquilo que eles representam na sua realidade.
Kishimoto (1996) destaca esta importância simbólica do brinquedo e o fato de ele colocar a criança na presença de reproduções de tudo que existe no cotidiano, na natureza, nas construções humanas e na realidade social.

Sobre o papel do brinquedo nas apropriações de imagens e de representações, também Brougère (1997) ressalta a sua importância, destacando que ele traz para a criança um suporte de ação, de manipulação, de conduta lúdica e de formas, imagens e símbolos a serem manipulados.

Concluindo, tendo em vista a criança como sujeito histórico e social, a brincadeira infantil e o uso de brinquedos passam a ter uma importância fundamental dentro do contexto pré-escolar, uma vez que estas atividades representam práticas educativas.

A brincadeira é, primordialmente, a forma pela qual a criança começa a aprender, com base na qual inicia a formação de seus processos de imaginação e criação, e se apropria das funções e dos valores sociais da cultura em que está inserida; é a sua primeira forma de humanização.

Se pensarmos a educação como a apropriação e a transformação de valores, pensamentos e conceitos do grupo em que estamos inseridos, como prática histórica e político-social, o brincar na pré-escola constitui uma prática pedagógica importante, uma vez que é através dele que se dá a construção de uma identidade infantil autônoma, crítica e criativa, ou seja, permite a formação de futuros cidadãos críticos e transformadores da realidade em que vivem.

\section{Garantindo a brincadeira no contexto pré-escolar}

Para que a brincadeira tenha lugar garantido no contexto escolar, ela precisa ser valorizada, estimulada e principalmente entendida na sua tão importante função educativa: a de propiciadora da constituição do indivíduo.

Oliveira (1995) entende que a promoção de atividades que favoreçam o envolvimento da criança em brincadeiras, principalmente aquelas que promovem a criação de situações imaginárias, têm nítida função pedagógica, e que a pré-escola poderia se utilizar deliberadamente desse tipo de situação para otimizar o processo de desenvolvimento das crianças.

Para que a pré-escola faça uso da função pedagógica do brincar é importante que alguns aspectos do ambiente físico e da organização temporal sejam considerados.

Rego (1995) cita que é importante que as crianças tenham espaço para brincar, assim como opção de mexer no mobiliário, como por exemplo montar casinhas, cabanas, tendas, etc. Complementa que o 
tempo que as crianças têm à disposição para brincar também deva ser considerado: ele deve ser suficiente para que as brincadeiras surjam, desenvolvam-se e se encerrem.

Wajskop (1995) salienta que, para que a escola forneça condições que garantam o aparecimento da brincadeira, é necessário que:

1. a rotina escolar contemple períodos razoavelmente longos entre as atividades dirigidas, para que as crianças se sintam à vontade para brincar;

2. existam materiais variados, organizados de maneira clara e acessível às crianças, de tal forma que possam deflagrar e facilitar o aparecimento das brincadeiras entre as mesmas. $\mathrm{O}$ acesso e a organização dos materiais devem levar em conta a idade das crianças, sendo seu uso coordenado pelo adulto responsável pelo grupo;

3. a sala onde as crianças passam a maior parte de seu tempo tenha uma tal configuração visual e espacial que facilite o desenvolvimento da imaginação. Os móveis, como mesas, bancos, cadeiras, etc., devem ser de fácil manipulação, para permitir a reorganização constante do local pelas crianças, e a construção de "casinhas", "cabanas", "lojas", "castelos", etc. É importante, ainda, garantir um canto com espelho, maquiagens, roupas e fantasias, para que as crianças possam utilizá-las nos períodos de jogo;

4. haja um período em que as crianças e o adulto responsável pelo grupo possam conversar sobre as brincadeiras que vivenciaram, as questões que surgiram, o material que utilizaram, os personagens que assumiram, os colegas com os quais interagiram;

5. a brincadeira seja incorporada no currículo como um todo, e as questões envolvidas no seu desenrolar possam fazer parte de pesquisas desenvolvidas em atividades dirigidas pelas crianças; ampliadas através de passeios, observação da natureza, projeção de vídeos, atividades envolvendo escuta de música, leitura, etc.;

6. o adulto seja elemento integrante das brincadeiras, ora como observador e organizador, ora como personagem que explicita, questiona e enriquece o desenrolar da trama, ora como elo de ligação entre as crianças e os objetos. Por fim, o adulto, como elemento mediador, deve estar sempre junto às crianças, acolhendo suas brincadeiras, atento aos seus questionamentos, auxiliando-as nas suas reais necessidades e na busca de compreensão e construção de estratégias de ação no contexto em que vivem.
Do exposto, podemos concluir que se a brincadeira é entendida e considerada na sua função pedagógica, ela precisa ser garantida e isto se faz considerando uma série de fatores. Entre eles, destacamos: o ambiente físico, o tempo, a rotina escolar, o preparo dos professores e educadores, aspectos que podem estimular, propiciar e garantir sua ocorrência no contexto pré-escolar.

Neste sentido, acreditamos que um referencial teórico que privilegie a construção histórico-cultural de conceitos relativos à educação da infância, ao papel da escolarização e das influências promovidas dentro desses contextos seja um guia orientador das práticas que venham a ser conduzidas e refletidas nessas instituições. A afirmação de Kramer (1989) sobre este modelo teórico explica, em grande parte, a escolha desse referencial para orientar nossa reflexão sobre a prática pedagógica. Diz a autora:

em Vygotsky não há lugar para dicotomias que isolem o fenômeno, fragmentando-o ou imobilizando-o de maneira artificial. Para ele tudo está em movimento e é causado por elementos contraditórios, coexistindo numa mesma totalidade rica, viva, em constante mudança (p.72).

\section{REFERÊNCIAS BIBLIOGRÁFICAS}

Brougère, G. (1997). Brinquedo e Cultura. São Paulo: Cortez.

Cerisara, A. B. (1995). A Educação Infantil e as Implicações Pedagógicas do Modelo Histórico-Cultural. CADERNOS CEDES: Implicações Pedagógicas do Modelo HistóricoCultural. 35, 65-78.

Cobb, P. (1998). Onde está a mente? Uma coordenação das abordagens sócio-cultural e cognitivo-construtivista. Em C. T. Fosnot (Org.). Construtivismo: Teorias, Perspectivas e Prática Pedagógica. (pp. 51 - 72), Porto Alegre: Artes Médicas.

Duarte, N. (1998). Concepções afirmativas e negativas sobre o ato de ensinar. CADERNOS CEDES. 44, 85-106.

Fosnot, C. T. (1998). Construtivismo: Uma Teoria Psicológica da Aprendizagem. Em C. T. Fosnot (Org.). Construtivismo: Teoria, perspectivas e prática pedagógica. (pp. 25-50), São Paulo: Artes Médicas.

Gould, J. S. (1998). Uma abordagem Construtivista do Ensino e da Aprendizagem em Artes da Linguagem. Em: C. T. Fosnot (Org.). Construtivismo: Teoria, perspectivas e prática pedagógica. (pp. 111-122), São Paulo: Artes Médicas.

Kishimoto, T. M. (1996). Jogo, brinquedo, brincadeira e a educação. São Paulo: Cortez 
Kramer, S. (1989). Com a pré-escola nas mãos: Uma alternativa curricular para a educação infantil. São Paulo: Ática.

Oliveira, B. (1992). A prática social global como ponto de partida e de chegada na prática educativa. Em B. Oliveira \& N. Duarte (Orgs.). Socialização do saber escolar. (pp. 91-105), São Paulo: Cortez.

Oliveira, M. K. de (1995). O Pensamento de Vygotsky como Fonte de Reflexão sobre a Educação. CADERNOS CEDES: Implicações Pedagógicas do Modelo HistóricoCultural. 35, 9-14.

Oliveira, M. K. de (1995). Vygotsky: aprendizado e desenvolvimento. Um processo sócio-histórico. São Paulo: Scipione.

Oliveira, Z. M. R. (1995). Interações Sociais e Desenvolvimento: A Perspectiva Sociohistórica. CADERNOS CEDES: Implicações do Modelo Histórico Cultural. 35, 51-64.

Rego, T. C. (1995). Vygotsky: uma perspectiva histórico cultural da educação. Petrópolis, Vozes.
Saviani, D. (1995). Pedagogia histórico-crítica: primeiras aproximações. São Paulo: Cortez.

Vygotsky, L. S. (1987). Pensamento e linguagem. São Paulo: Martins Fontes.

Vygotsky, L. S. (1991). A formação social da mente. São Paulo: Martins Fontes.

Vygotsky, L. S., Luria, A. R. \& Leontiev, A. N. (1988). Linguagem, desenvolvimento e aprendizagem. São Paulo: Ícone Edusp.

Wajskop, G. (1995). Brincar na pré-escola. São Paulo: Cortez.

Recebido em 08/02/2001

Revisado em 23/04/2001

Aceito em 30/05/2001 